\title{
Psychosocial Correlates of Motivation for Academic Accomplishment among University Students
}

\author{
Ayman M. Hamdan-Mansour1,2, Shaher H. Hamaideh³, Saleh N. Azzeghaiby4, \\ Salah I. Hanouneh ${ }^{4}$, Ahmad E. Aboshaiqah ${ }^{5}$ \\ ${ }^{1}$ Al Farabi College, Riyadh, KSA \\ ${ }^{2}$ Faculty of Nursing, The University of Jordan, Amman, Jordan \\ ${ }^{3}$ Community and Mental Health Nursing Department, Faculty of Nursing, The Hashemite University, Zarka, \\ Jordan \\ ${ }^{4}$ Al-Farabi College for Dentistry and Nursing, Al-Farabi College, Riyadh, KSA \\ ${ }^{5}$ College of Nursing, King Saud University, Riyadh, KSA \\ Email: aymanjabay@gmail.com, shaher29@hu.edu.jo, talal5656@yahoo.com, shanouneh@yahoo.com, \\ aaboshaiqah@ksu.edu.sa
}

Received 11 November 2014; revised 8 December 2014; accepted 3 January 2015

Copyright (C) 2015 by authors and Scientific Research Publishing Inc.

This work is licensed under the Creative Commons Attribution International License (CC BY). http://creativecommons.org/licenses/by/4.0/

(c) (†) Open Access

\begin{abstract}
Motivation has been a concept of interest for behavioral and cognitive scientists for its significant contribution to human behaviors and conducts. The purpose of this study was to examine the relationship between intrinsic motivation to academic accomplishment (IMTA) and psychosocial wellbeing among university students in Jordan. Methods: cross sectional correctional design utilized to collect data from 218 university students in regards to motivation to academic accomplishment, social support, life satisfaction, optimism, and depressive symptoms. The results showed that university students in Jordan had low moderate level of IMAT, and that IMAT had positive association with perceived social support from family $(r=0.17, \mathrm{p}<0.05)$, life satisfaction $(r=0.14, \mathrm{p}<0.05)$, and optimism $(r=0.19, \mathrm{p}<0.001)$. None of the psychosocial factors were found to be significant predictor of IMATA, while age group and working status were significant ones (p $<0.05$ ). Moreover, there was significant difference in IMTA in regards to age groups showing that $1^{\text {st }}$ and $2^{\text {nd }}$ year's students had higher IMTA than their counterparts in higher academic levels. Implication for mental health counselors at the students' health services and centers were discussed.
\end{abstract}

\section{Keywords}

Motivation to Academic Accomplishment, Social Support, Life Satisfaction, Optimism, Depressive

How to cite this paper: Hamdan-Mansour, A.M., Hamaideh, S.H., Azzeghaiby, S.N., Hanouneh, S.I. and Aboshaiqah, A.E. (2015) Psychosocial Correlates of Motivation for Academic Accomplishment among University Students. Open Journal of Medical Psychology, 4, 1-8. http://dx.doi.org/10.4236/ojmp.2015.41001 


\section{Symptoms}

\section{Introduction}

Motivation became a concept of interest for behavioral and cognitive scientists for its significant contribution to human behaviors and conducts [1]. The concept was targeted by researches interested in investigating factors contributing to university students' achievement. Motivation that is defined as "cognitive, emotional, and behavioral indicators of students' investment in and attachment to education” [2], has been linked to learning stimulation and academic success [3]. Previous studies showed that motivation for academic accomplishment was associated with a number of cultural, environmental and educational factors [4]-[6]. Although the role of psychosocial health status was found to be an influence component on university students functioning, the impact of psychological factors on academic accomplishment is not adequately addressed in the literature. According to Kitzrow [7], college students have greater psychosocial needs than expected, and those needs are psychological and mental rather than developmental ones. College students are also found to be at risk for a number of mental and psychosocial problems such as stress, depression, substance use, hostility, and anger that have a direct impact on their academic performance and social functioning [8]-[10].

Moreover, Jordanian studies found that university students have moderate perception of social support and stress, moderate level of perception of psychological wellbeing, and a number of physical complaints [8] [11]. The studies, in general, indicate that university students are at risk for a number of psychological and physical health problems that may interfere with their ability to adjust and be motivated for academic accomplishment. Malkoush [12] maintained that academic adjustment and degree of available social support were associated positively among university students in Jordan, which emphasized the importance of psychological wellbeing to students' academic achievement.

Although a number of previous studies have emphasized the role of psychological factors in students' academic performance [3] [13], studies that connect motivation for academic achievement/accomplishment to psychosocial health status among university students have not been addressed sufficiently. In Jordan, adequate studies conducted during the past decade addressed the mental and psychosocial health of university students. However, these studies addressed the bio-psychosocial wellbeing and physical health and risk factors [8] [14], whereas, no study addressed to examine the association of these factors to students' academic accomplishment. Therefore, the purpose of this study was to examine the relationship between motivation for academic accomplishment and psychosocial wellbeing among university students in Jordan. The research questions are:

1. What is the prediction power of psychosocial wellbeing, depressive symptoms, optimism, life satisfaction, and social support from friends and family, on motivation for academic accomplishment among university students in Jordan?

2. Is there a difference in motivation for academic accomplishment related to selected demographic characteristics among university students in Jordan?

\section{Methods}

Design: this is a descriptive correlational study. Data collected using a self-administered questionnaire from six governmental and private universities. A package of five self-reported questionnaires, in addition to the author-developed demographic profile sent to students who expressed interest in participation. Prior to data collection, the primary investigator obtained approval from the Research Committee at the Faculty of Nursing at the University of Jordan and the targeted universities. Subject's identification number assigned for each subject at the beginning of the study. The information obtained about the subjects of the study kept confidential. All files kept in locked cabinets at the Faculty of Nursing, University of Jordan. All projects electronic versions kept in the primary investigator's computer. The package introduced to students translated into Arabic language. Four hundred packages sent out and 218 returned. The response rate was 55\%.

\subsection{Participants}

About 218 university students filled and returned a battery of five self-reported questionnaires. The students 
represent three governmental universities and three private universities. Students from governmental universities represented $62 \%(n=135)$, while $38 \%(n=83)$ came from private universities.

\subsection{Measurements}

For the purpose of this study, instruments translated into Arabic language. Numbers of procedures used to determine the reliability and validity of the tool. The tools was first translated into Arabic language by a research assistant and back translated into English language another independent research assistant. The two English forms (the original and the translated) compared in terms of conceptual rather than literal meaning of the items. The translator and the back translator met to examine the differences in the two forms. Pilot testing was conducted using students $(n=20)$ who are bilingual requesting their appraisals for the appropriateness of the translation. The scales checked for cultural variation. In addition, the research package included an author-developed profile that used to obtain demographic and personal information.

1. Motivation for Academic accomplishment measured using the Intrinsic Motivation to accomplish subscale of the Academic Motivation Scale (IMTK) (AMS) [15]. The AMS consists of 28 items, in which students respond to the question stem "Why are you going to college?" the Intrinsic Motivation to Accomplish (IMTA) is formed of four items that are rated on a scale, ranging from one (does not correspond at all) to seven (corresponds exactly). A high score on a subscale indicates high endorsement of that particular academic motivation. In this study, Cronbach's Alpha was 0.76 .

2. Depressive symptoms measured using the Arabic version of Beck Depression Inventory-II (BDI-II) [16]. The Beck Depression Inventory-II (BDI-II) used to assess patients' depressive symptoms, which contain items that measure cognitive-affective symptoms and attitudes, impaired performance and somatic symptoms [16]. This inventory contains 21 questions answered on a four-point Likert scale in which represents the absence of symptoms and 3 represents an extreme problem. The total score ranges from 0 - 63. The established standard cut-off points are as follows: 0 - 13 for no or minimal symptoms, 14 - 19 for mild symptoms, 20 - 28 for moderate symptoms and 29 - 63 for severe symptoms.

3. Perceived social support measured using the Perceived Social Support (PSS) Scale [17]. The PSS is a 40-item scale that measures the nature of the perceived social support from family and friends. The PSS consists of two subscales, perceived social support from family (PSS-Fa) and perceived social support from friends (PSS-Fr). Each of subscale scores range from zero to 20. Lower scores indicate lower perception of perceived social support, while higher scores suggest higher perception of perceived social support [17]. The scales have demonstrated good internal consistency ranging from 0.88 to 0.91 for the family subscale and from 0.84 to 0.90 for the friend subscale [17]. The test-retest reliability reported and ranged from 0.80 to 0.81 . Construct validity shows fairly low correlation coefficient of 0.3 [17]. In this study, Cronbach’s Alpha was 0.76 .

4. Optimism measured using the Life Orientation Test (LOT-R) [18]. The LOT-R designed to measure optimisms by assessing the generalized outcome expectancies of individuals. Each item scaled on a five point Likert scale. The responses ranges from strongly agree to strongly disagree. Cronbach's alpha for the scale was 0.76 and test-retest estimated at 0.79 [18]. In this study, Cronbach's Alpha was 0.73 .

5. Life satisfaction measured using the Satisfaction with Life Scale [19]. This is a general measure of life satisfaction, which consisted of five statements. Participants asked to rate each statement according to the following seven-point scale: 1) strongly disagree, 2) disagree, 3) slightly disagree, 4) neither agree nor disagree, 5) slightly agree, 6) agree, and 7) strongly agree. The scores of the total scale ranges from five to 35 and interpreted as follow: from 31 - 35 (eextremely satisfied), from 26 - 30 (satisfied), from 21 - 25 (slightly satisfied), 20 (neutral), from 15 - 19 (slightly dissatisfied), from 10 - 14 (dissatisfied), and 5 - 9 (extremely dissatisfied). The test-retest reliability estimated to be 0.87 [19].

Potential covariates: variable such as gender, age group, student's faculty, and university academic year, treated as covariates. The demographic information obtained from an investigator-developed subject profile.

\section{Results}

\subsection{Demographic Data}

The sample consisted of 218 university students after screening and cleaning. Ninety-two students (42\%) were 
males and 126 (58\%) were females. Almost $60 \%$ of the students were in the second and third academic year while $24 \%$ were in their fourth-academic year. Twenty percent $(n=44)$ of the students enrolled in humanistic faculties while $40 \%(n=88)$ and $34 \%(n=86)$ were enrolled in scientific and medical faculties respectively. About $12 \%(n=29)$ students reported that they work besides studying, while 79\% $(n=188)$ reported not.

\subsection{Motivation for Academic Accomplishment}

Regarding student' intrinsic motivation, the analysis showed that the mean score for students was 17.2 (SD = 2.1), with scores ranging from 14 to 18 . About $50 \%(n=109)$ of the students had a score of 17 or less, and $75 \%$ of them $(n=164)$ had a score of 19 or less indicating that students had moderate to low level of intrinsic motivation.

\subsection{Psychosocial Health Status}

The analysis showed that the mean score for BDI was $15.7(\mathrm{SD}=8.6)$. Seventy six percent of the students $(\mathrm{n}=$ 164) scored 10 and above on the BDI indicating that almost $75 \%$ of the students reported themselves having mild to severe depression. The results also showed that 31\% $(n=67)$ had mild depression, $29 \%(n=63)$ had moderate depression, $16 \%(n=35)$ had severe depression, and only $24 \%(n=52)$ were not depressed.

Regarding life satisfaction, the analysis showed that students' mean score was 22.3 (SD $=6.2$ ), and about $75 \%$ ( $n=164$ ) of the students had a score of 18 or above. This indicates that students had moderate to high level of life satisfaction. In addition, the analysis showed that $50 \%(n=109)$ of the students had a score between 18 and 27 that confirms that students had high level of life satisfaction. Regarding perceived social support, the mean score for all students on the perceived social support from friends (PSS-Fr) was 13.1 (SD = 4.3) and perceived social support from family (PSS-Fa) was 12.1 (SD = 5.1) (see Table 1). For females, the mean scores of PSS-Fr and PSS-Fa were 13.5 (SD = 4.3) and 12.5 ( $(\mathrm{SD}=5.2)$ respectively, while the male students' mean scores of PSS-Fr and PSS-Fa were $12.2(\mathrm{SD}=4.0)$ and $11.4(\mathrm{SD}=4.7)$. Related to optimism, the analysis showed that the mean score was $34.1(\mathrm{SD}=4.7)$ with scores ranging from 10 to 50 . The analysis showed that $50 \%$ of the sample had a score of $31 \%$ to $38 \%$ and $75 \%(n=164)$ had a score of 31 or above. The results indicate that students, in general, had high level of optimistic feelings.

\subsection{Bivariate Analysis}

As shown in Table 1, the correlations matrix using Pearson $r$ (see Table 1), showed that there was a positive and significant correlation between intrinsic motivation to accomplishment (IMTA) and optimism and life satisfaction, and perceived social support from family $(\mathrm{p}<0.05)$. This infers that students who have higher level of optimism life satisfaction, and perceived social support from family are more likely to have higher level if intrinsic motivation for accomplishment. Moreover, depressive symptoms and perceived social support from friends had no significant correlation with academic accomplishment.

Regarding differences in IMTA related to demographic characteristics of students, the analysis (see Table 2) showed that there was a significant difference between students in regards to their age group $\left(\mathrm{F}_{3,218}=4.47, \mathrm{p}=\right.$ 0.005). The results indicate that students at their first and second year of university life had higher level of

Table 1. Correlation matrix of psychosocial factors and IMTA among university students in Jordan ( $\mathrm{N}=218)$.

\begin{tabular}{|c|c|c|c|c|c|c|}
\hline & Depression & Optimism & LS & PSSFR & PSSFA & IMTA \\
\hline Depression & -- & & & & & \\
\hline Optimism & $-0.27^{* *}$ & -- & & & & \\
\hline LS & $-0.25^{* *}$ & $0.29^{* *}$ & -- & & & \\
\hline PSSFR & 0.07 & $-0.25^{* *}$ & -0.12 & -- & & \\
\hline PSSFA & $0.22^{* *}$ & -0.09 & $-0.17^{*}$ & $0.32^{* *}$ & -- & \\
\hline IMTA & 0.10 & $0.19^{* *}$ & $0.14^{*}$ & 0.12 & $0.17^{*}$ &.-- \\
\hline
\end{tabular}

${ }^{* *}$ Correlation is significant at the 0.01 level (2-tailed). ${ }^{*}$ Correlation is significant at the 0.05 level (2-tailed). IMTA: Intrinsic motivation to accomplishment. PSSFR: Perceived social support from friends. PSSFA: Perceived social support from Family. LS: Life satisfaction. 
Table 2. Differences in IMTA related to demographic characteristics of university students in Jordan $(\mathrm{N}=218)$.

\begin{tabular}{|c|c|c|c|c|c|c|c|c|}
\hline & \multirow{2}{*}{ Variables } & & \multirow{2}{*}{$\mathbf{M}$} & \multirow{2}{*}{ SD } & \multicolumn{4}{|c|}{ Test statistics } \\
\hline & & & & & t-test & p value & F test & $p$ value \\
\hline & \multirow{2}{*}{ Gender } & Male & 17.6 & 2.7 & \multirow{2}{*}{1.17} & \multirow{2}{*}{0.21} & & \\
\hline & & Female & 17.1 & 2.4 & & & & \\
\hline & \multirow{2}{*}{ Working status } & Yes & 17.1 & 2.5 & \multirow{2}{*}{0.92} & \multirow{2}{*}{0.36} & & \\
\hline & & No & 17.7 & 2.8 & & & & \\
\hline \multirow{6}{*}{ IMTA } & \multirow{3}{*}{ Age group } & $17-20 y$ & 18.9 & 2.7 & & & \multirow{3}{*}{4.47} & \multirow{3}{*}{0.005} \\
\hline & & $20-22 y$ & 17.1 & 2.4 & & & & \\
\hline & & $>22 y$ & 16.3 & 2.3 & & & & \\
\hline & \multirow{3}{*}{ Student faculty } & Scientific & 17.5 & 2.8 & & & \multirow{3}{*}{0.97} & \multirow{3}{*}{0.38} \\
\hline & & Health & 16.9 & 2.2 & & & & \\
\hline & & Humanistic & 17.1 & 2.3 & & & & \\
\hline
\end{tabular}

IMTA: Intrinsic motivation to accomplishment.

motivation for academic accomplishment than those who are at higher academic levels. However, the analysis showed that there were no differences in IMTA between students in regards to their gender, students' faculty or their working status.

To examine whether social support, life satisfaction, optimism and depression are significant predictors of IMTA among university students controlling for the demographic and personal characteristics (age, gender, working status, and type of students' faculty), two-steps multiple hierarchical regression analysis was performed. The results (see Table 3 ) showed that model-1 that contained demographics and personal characteristics explained $8 \%\left(R^{2}=0.08\right)$ of the variance in IMAT. The model was significant $\left(\mathrm{F}_{4,218}=3.96, \mathrm{p}=0.004\right)$. In this model, students working status and age group were significant predictor of IMTA. After entry of social support, life satisfaction, optimism and depression at step 2, the total variance explained by the model as a whole was $14 \%\left(R^{2}=0.14\right)$ and was significant $\left(\mathrm{F}_{8,218}=3.2, \mathrm{p}=0.001\right)$. The variables in step-2 explained an additional $6 \%$ of variance in IMTA. In Model 2, working status and age group remained significant predictors, while none of the psychosocial factors found to be significant predictor of IMTA. The results infer that students' demographic and personal characteristics are the significant factors that contribute to students' intrinsic motivation for academic accomplishment, on the other hand; students' psychological and social health factors seems not to contribute to their IMTA.

\section{Discussion}

This study came to address an important issue of concern for higher education systems. The study investigated the psychosocial and demographic factors that associate with university students' academic accomplishment. A significant finding in this study showed that students had low to moderate level of motivation to academic accomplishment. The results do not agree with previous studies that collogues' students had high level for academic achievement [20]. Although the two populations in this study and in Hamaideh's study [20] share the same culture, Arabs, the two educational systems vary in terms of environmental and economical support that the students receive. This difference between the two systems supported by Robbins and colleagues [21] who reported that financial support and social involvement are among the main factors that influence students' motivation for academic accomplishment.

The study also found that psychosocial factors (optimism, life satisfaction and perceived social support from family) correlated significantly with motivation to academic accomplishment, although later found not to be significant predictors. However, depressive symptoms and perceived social support from friends were not correlated with motivation to academic accomplishment. The results partially agree with previous studies [22]-[24] whom found that optimism and life satisfaction were associated positively with academic achievement that 
Table 3. Two steps multiple hierarchal regressing IMTA on depressive symptoms, social support, life satisfaction, and optimism controlling for demographic and personal characteristics among university students in Jordan $(\mathrm{N}=218)$.

\begin{tabular}{|c|c|c|c|c|}
\hline \multirow{2}{*}{ Variables } & \multicolumn{2}{|c|}{ Model 1} & \multicolumn{2}{|c|}{ Model 2} \\
\hline & $\beta$ & p-value & $\beta$ & p-value \\
\hline Gender & -0.563 & 0.317 & -1.115 & 0.267 \\
\hline Age group & -1.072 & 0.006 & -2.899 & 0.004 \\
\hline Student faculty & -0.121 & 0.681 & -0.191 & 0.849 \\
\hline working status & 1.804 & 0.013 & 2.611 & 0.010 \\
\hline Depressive symptoms & & & 0.206 & 0.837 \\
\hline Optimism & & & -1.759 & 0.080 \\
\hline Life satisfaction & & & -0.804 & 0.422 \\
\hline PSS-Fr & & & 1.403 & 0.162 \\
\hline PSS-Fa & & & 0.782 & 0.435 \\
\hline$R^{2}$ & 0.08 & 0.004 & 0.14 & 0.001 \\
\hline Adjusted $R^{2}$ & 0.06 & . & 0.09 & \\
\hline$R^{2}$ change & - & . & 0.06 & \\
\hline
\end{tabular}

PSS-Fr: Perceived social support from friends. PSS-Fa: Perceived social support from family.

agrees with findings in this study. Hamaideh and Hamdan-Mansour [20] found that depression was a strong predictor of student's academic achievement that does not agree with results of this study. One explanation is related to factors used to measure academic achievement. In this study, we have measured the intrinsic motivation to academic achievement which is connected to perception and cognitive components, while in the other studies [20] [24] academic achievement has been measured in terms of GPA and motivation for academic achievement needs. This emphasizes the multifaceted aspect of academic achievement and using grading system might have difference outcomes than students' perception.

Another significant finding of this study is that there were no differences in motivation to academic accomplishment in regards to gender or type of student's faculty. The difference found between those at their first and second year of university life and those who are at advanced academic level (academic level), and between those who work and those who are not. The results are inconsistent with previous reports who found that male students have higher motivation for academic achievement than female ones [20] [25]. One possible explanation could be related to education system in which students in the previous studies belong to an educational system that separate female and male students campuses at the universities, and that students belongs to health faculties. In this study, students belong to education system in which male and female students are not separated in campus and comes from different faculties and universities. The study emphasizes the importance of investigating the environmental and sociocultural factors of students to better understand the factors that contribute to motivation for academic achievement at high education institutions.

One limitation of this study is that motivation for academic accomplishment has been measured using a unidimensional approach, while using multifaceted mix model approach would provide better understanding for motivation for academic achievement and performance among university students.

\section{Conclusion}

This study found that almost $75 \%$ of the students had moderate low intrinsic motivation for academic accomplishment, and that life satisfaction, optimism, perceived social support from family, working status, and age are significant associates of motivation for academic accomplishment. The study has an implication for mental health counselors at the students' health services and centers. In their periodic assessment, mental health counselors have to screen student for psychosocial health indicators of academic achievement that include depression, 
stress, social support, optimism and life satisfaction. In addition, health counselors have to recognize that younger students have high level of motivation than older ones, and there is a need to develop certain measures and programs to sustain students' motivation and enhance their psychological and social wellbeing. There is a need to enact and implement legislations that allow for periodic psychological health assessment among university students and promote sustainable preventive programs. Instructors and academic personnel have also to consider the psychosocial and mental status and its impact on the student's academic performance. It is recommended that faculties and administrators need to enhance student-faculty interaction at the universities, and that faculties significant role in providing support and promoting students' academic accomplishment. Further studies recommend addressing the sociocultural factors of students at the universities.

\section{References}

[1] Deci, E.L. and Ryan. R.M. (2008) Self-Determination Theory: A Macrotheory of Human Motivation, Development and Health. Canadian Psychology, 49, 182-185. http://dx.doi.org/10.1037/a0012801

[2] Tucker, C.M., Zayco, R.A. and Herman, K.C. (2002) Teacher and Child Variables as Predictors of Academic Engagement among Low-Income African American Children. Psychology in the Schools, 39, 477-488. http://dx.doi.org/10.1002/pits.10038

[3] Sobral, D.T. (2008) Student-Selected Courses in Medical School: Scope and Relationships. Medical Teacher, 30, 199205. http://dx.doi.org/10.1080/01421590701754169

[4] Hamdan-Mansour, A., Arabiat, D., Sato, T., Imoto, A. and Obiad, B. (2011) An Investigation into Marital Abuse and Psychological Wellbeing among Women in the Southern Region of Jordan. Journal of Transcultural Nursing, 22, 265273. http://dx.doi.org/10.1177/1043659611404424

[5] Kember, D., Hong, C. and Ho, A. (2008) Characterizing the Motivational Orientation of Students in Higher Education: A Naturalistic Study in Three Hong Kong Universities. British Journal of Educational Psychology, 78, 313-329. http://dx.doi.org/10.1348/000709907X220581

[6] Kusurkar, R., Croiset, G., Kruitwagen, C. and Ten Cate, O. (2010) Validity Evidence for the Measurement of the Strength of Motivation for Medical School. Advance in Health Sciences Education, 16, 183-195. http://dx.doi.org/10.1007/s10459-010-9253-4

[7] Kitzrow, M. (2003) The Mental Health Needs of Today’s College Students: Challenges and Recommendations. National Association of Student Personnel Administrators, 41, 167-181.

[8] Hamdan-Mansour, A., Dardas, L., AbuIsbaa, M. and Nawafleh, H. (2012) Predictors of Anger among University Students in Jordan. Children and Youth Service Review, 34, 474-479. http://dx.doi.org/10.1016/j.childyouth.2011.12.004

[9] Hamdan-Mansour, A. and Dawani, H. (2008) Social Support and Stress among University Students in Jordan. International Journal of Mental Health and Addiction, 6, 442-450. http://dx.doi.org/10.1007/s11469-007-9112-6

[10] Marmorstein, N.R. and Iacono, W.G. (2004) Major Depression and Conduct Disorder in Youth: Associations with Parental Psychopathology and Parent-Child Conflict. Journal of Child Psychology and Psychiatry, 45, 377-386. http://dx.doi.org/10.1111/j.1469-7610.2004.00228.x

[11] Khalil, A., Darawad, M., Al-Gamal, E. and Hamdan-Mansour, A. (2012) Predictors of Dietary and Fluid Nonadherence in Jordanian Patients with End-Stage Renal Disease Receiving Hemodialysis: A Cross-Sectional Study. Journal of Clinical Nursing, 22, 127-136. http://dx.doi.org/10.1111/j.1365-2702.2012.04117.x

[12] Malkoush, R. (2000) Social Support and Scholastic Adjustment among Students of the University of Jordan. Dirasta Journal, 27, 161-172.

[13] Nieuwhof, M.G.H., Ten Cate, T.J., Oosterveld, P. and Soethout, M.B.M. (2004) Measuring Strength of Motivation for Medical School. Medical Education Online, 9.

[14] Hamdan-Mansour, A. (2010) Predictors of Hostility among University Students in Jordan. Scandinavian Journal of Caring Sciences, 24, 125-130. http://dx.doi.org/10.1111/j.1471-6712.2009.00695.X

[15] Vallerand, R.J., Pelletier, L.G., Blais, M.R, Brière, N.M., Senécal, C. and Vallières, E.F. (1992) The Academic Motivation Scale: A Measure of Intrinsic, Extrinsic, and Amotivation in Education. Educational and Psychological Measurement, 52, 1003-1017. http://dx.doi.org/10.1177/0013164492052004025

[16] Beck, G., Steer, R. and Brown, G. (1996) Manual for the Beck Depression Inventory-II. Psychological Corporation, San Antonio.

[17] Procidano, M. and Heller, K. (1983) Perceived Social Support Scale. American Journal of Community Psychology, 11, 1-24. http://dx.doi.org/10.1007/BF00898416 
[18] Scheier, M.F., Carver, C.S. and Bridges, M.W. (1994) Distinguishing Optimism from Neuroticism (and Trait Anxiety, Self-Mastery, and Self-Esteem): A Reevaluation of the Life Orientation Test. Journal of Personality and Social Psychology, 67, 1063-1078. http://dx.doi.org/10.1037/0022-3514.67.6.1063

[19] Diener, E., Emmons, R.A., Larsen, R.J. and Griffin, S. (1985) The Satisfaction with Life Scale. Journal of Personality Assessment, 49, 71-75. http://dx.doi.org/10.1207/s15327752jpa4901_13

[20] Hamaideh, S. and Hamdan-Mansour, A. (2014) Psychological, Cognitive, and Personal Variables That Predict College Academic Achievement among Health Sciences Students. Nurse Education Today, 34, 703-708. http://dx.doi.org/10.1016/j.nedt.2013.09.010

[21] Robbins, S., Lauver, K., Davis, H., Langley, R. and Carlstorm, A. (2004) Do Psychological and Study Skill Factors Predict College Outcomes? A Meta-Analysis. Psychological Bulletin, 130, 261-288. http://dx.doi.org/10.1037/0033-2909.130.2.261

[22] AllaEddeen, J. and Hamaideh, S. (2009) Depressive Symptoms and Their Correlates with Locus of Control and Satisfaction with Life among College Students. European Journal of Psychology, 4, 71-103.

[23] Rittman, A.L. (1999) Psychological Factors Related to Academic Performance and Retention in 1st Year College Student. Psi Chi Journal of Undergraduate Research, 4, 27-32.

[24] Rode, J., Arthaud-Day, M., Mooney, C., Near, J., Baldwin, T., Bommer, W. and Rubin, R. (2005) Life Satisfaction and Student Performance. Academic Management of Learning and Education, 4, 421-433. http://dx.doi.org/10.5465/AMLE.2005.19086784

[25] Al-Alwan, I. (2009) Association between Scores in High School, Aptitude and Achievement Exams and Early Performance in Health Sciences College. Saudi Journal of Kidney Disease and Transplant, 20, 448-453. 
Scientific Research Publishing (SCIRP) is one of the largest Open Access journal publishers. It is currently publishing more than 200 open access, online, peer-reviewed journals covering a wide range of academic disciplines. SCIRP serves the worldwide academic communities and contributes to the progress and application of science with its publication.

Other selected journals from SCIRP are listed as below. Submit your manuscript to us via either submit@scirp.org or Online Submission Portal.
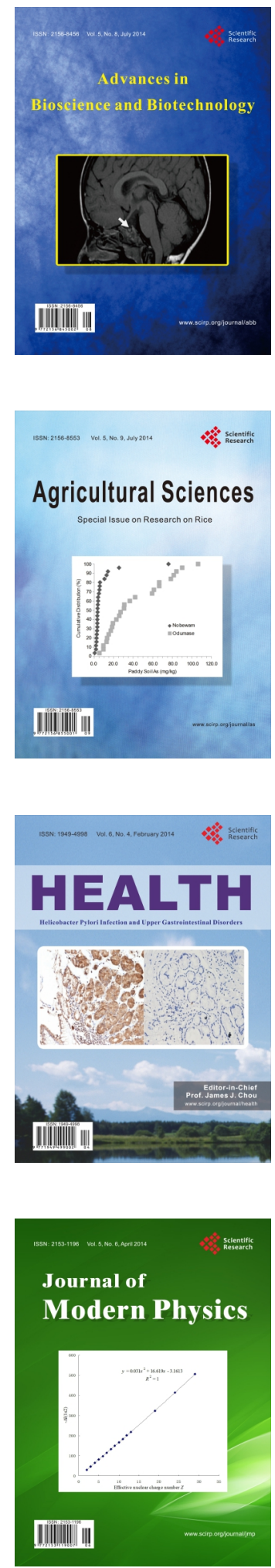
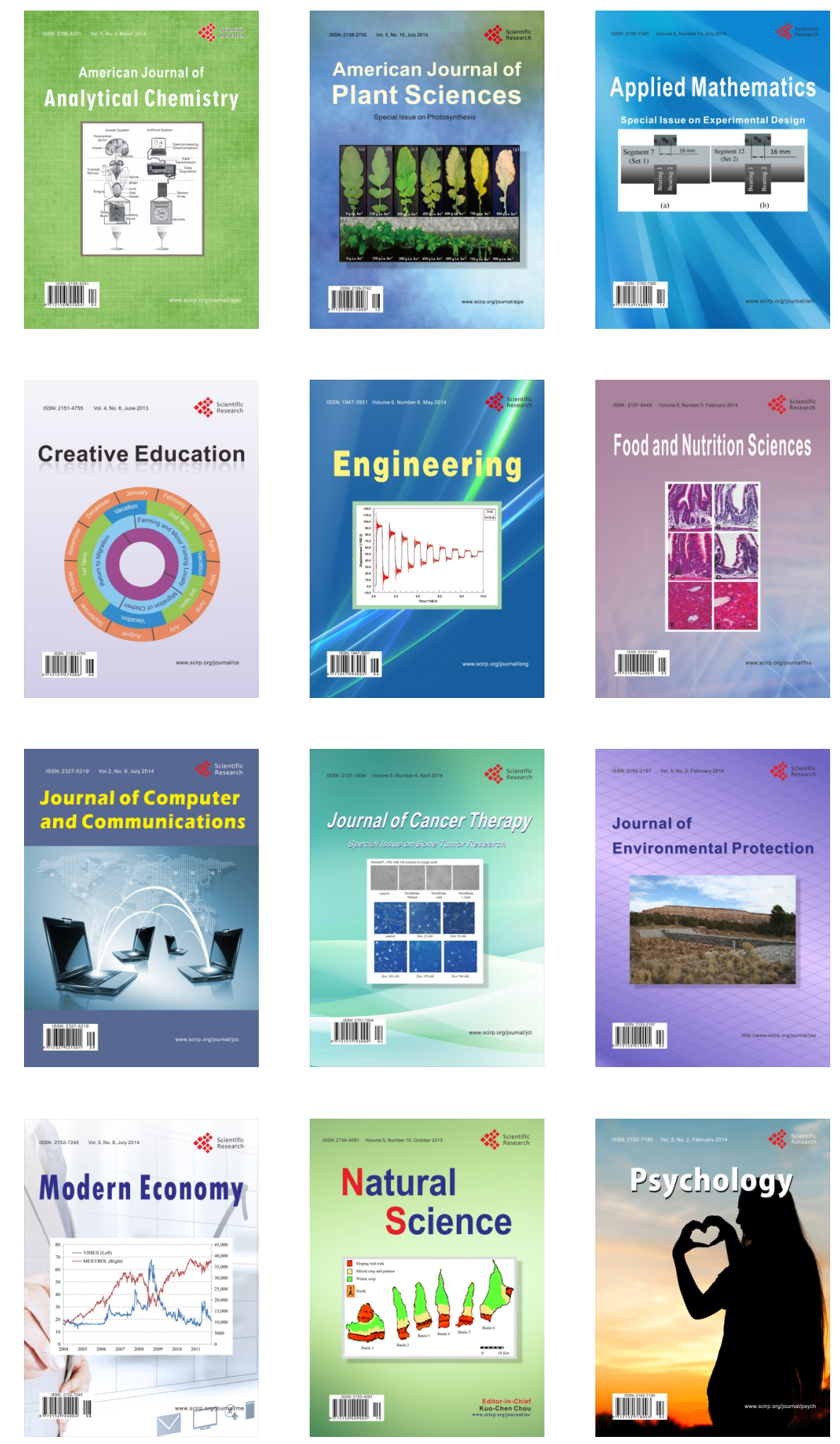